\title{
Going to the Movies in Egypt
}

\author{
By Mustafa Mahmoud Yousry \\ Spring 2010 Issue of KINEMA \\ GOING TO THE MOVIES: AN INVESTIGATION OF THE FACTORS WHICH INFLU-
ENCE THE EGYPTIAN AUDIENCES' CHOICES OF MOTION PICTURES
}

Study rationale

According to Vale (1982), researchers could learn a great deal by studying and comparing audiences' choices of motion pictures. The audiences' choices show an interest that could betray their latent preferences, desires and perhaps their problems and difficulties. The uses and gratifications theory states that "people's media consumption patterns are intended actions on the part of the viewers" and that "individuals do make conscious choices about what they see and read in the media" (Salwen and Stacks, 2006). This basically means that audiences do not always choose to see a specific movie for the same reasons... The present study, therefore, is aiming to find out the most influential factors that get the Egyptian audience to go see a specific movie at film theatres. Consequently, this main objective, when realized, could help us, even in part, to identify if movie watching is still popular to the general Egyptian public and discover if other ways of viewing a movie had become more popular. The study findings may benefit the Egyptian film production and distribution companies in reaching their audience the best way possible once they know exactly what motivates an audience to go see the film.

\section{Research questions}

Through the present study, the researcher will look at what helps the Egyptian audiences to decide the movie they want to see in film theatres and what motivates them to choose a specific movie from the many available. In particular, the study will attempt to find out the relationship between Egyptian audiences' movie-viewing choices and each of the following seven factors/media:

- The director of a movie

- Reading or watching movie critiques in newspapers, magazines, TV, etc.

- Watching general advertising in newspapers, magazines, TV, etc.

- Perceived movie-star power

- Watching trailers for an upcoming movie

- Word-of-mouth comments that are heard about a movie

- Preferences in movie genre

\section{Introduction}

The main purpose of the present research is to study the Egyptian movie-viewing audiences and to see what motivates them to go see a particular movie in a film theatre. Previous Egyptian studies have only concentrated on examining the socio-economic aspects of Egyptian audiences such as looking at income levels and leisure activities in order to see the impact of movie watching on the Egyptian society in general. This new study is more specific, investigating how a person is initially enticed to go see a movie, whether this is through word of mouth, exposure to various media outlets ranging from movie previews to movie critiques in a newspaper or on TV, the drawing power of the cast or director, and so on. Actually, it is the researcher's hope to find that a good majority of the Egyptian audience base their movie-viewing choices on genre and reviews rather than on word-of-mouth or on who acts in the movie.

Internationally, the study of the effects of movies on people can be traced back to the early 20th century. In January 1929, a group of University of Chicago undergraduates were given a project in which they had to write autobiographical accounts of their movie-going experiences and the impact that movies had on their lives. There were mixed responses from participants, from those who thought that movies were beneath them and that they were "a lower order of art" to those who felt that movies were "guiding factors" in their lives (Fuller, 1996). A similar study was performed during World War II in Vienna. In this case, adults were surveyed and interviewed about their movie-going interests. The important point about the Vienna study was that relaxation was the primary motive for going to the movies (Austin, 1989). The current study already assumes that Egyptian audiences go to the movies for some relaxation, but the researcher wants 
to know beyond the idea of relaxation and look at the influence of trailers, directors, movie stars, genre, advertisements, critiques, and word of mouth on movie audience.

In 1957, a survey was conducted to find out about Americans' movie-going behaviour (Austin, 1989). The resulting report was entitled, The Public Appraises Movies, and included interviews conducted between June and July of 1957 with individuals who were 15 years and older. Interviewees were asked to give what they thought were the main reasons people go to the movies (Austin, 1989). The majority of reasons for attending movies centred on recreation and entertainment. Other reasons included passing time, habit, just because they wanted to, to see a movie they were interested in, to see a certain actor or actress, educational purposes, had read the book about a movie, had seen interesting advertising, had heard about the movie from someone else, to get away from everyday routine, relaxation, and because they were tired of watching television (Austin 1989). Another study of Soviet audience in 1966 found seven reasons for movie attendance; for relaxation, to find something new, to experience a sharp plot, to see an actor's performance, to listen to music in the movie, because they had no where else better to spend leisure time, and to see the skill in shooting a film (Austin, 1989). These reasons mention some of the variables that will be used in the current study, but they do not take into account the ideas of media use and exposure, including advertisements, trailers, and critiques.

Two more studies came in 1977; both reported that audiences go to the movies for the aesthetic experience that movies provide, the desire to relax, the desire to be entertained, the ability of movies to provide new experiences, and the ability of movies to allow for learning (Austin, 1989). A research report published by the Newspaper Advertising Bureau in 1986 showed that time has changed the movie-going experience. It stated that in 1946, the average American went to the movies 29 times a year; by 1984, the average was down to five times (Newspaper Advertising Bureau, 1986). This study, performed in 1985, used a sample of 1,000 respondents who were contacted by telephone using random-digit dialling techniques. One respondent was interviewed from each household called, and the sample of 1,000 was "balanced on age and sex" (Newspaper Advertising Bureau, 1986). The 1986 research report showed how people learn about a particular movie, the effects of cable and VCR usage on the movie-going public, and activities people have engaged in instead of going to a movie. This last study focused more on "who" goes to the movies and with whom rather than "why" people go to the movie; i.e., the inherent characteristics that prompt people to see a specific film. During the eighties too, Litman conducted an empirical study of theatrical movies and why some are successful and some are not. He examined this from the aspects of the scheduling of a movie's release, the marketing scheme, and the total creativity used to create the movie. He acknowledged the fact that people will see movies with their favourite stars, just as the current study will look at the effects of movie-star power on movie-viewing choice. Litman also looked at the marketing campaign for a movie that relates to the use of trailers and advertisements in the current study (Litman, 1983). In 1998, Dr. Stuart Fischoff of California State University did a film-choice study. Fischoff looked at how movies obtain "all-time favourite status" using movie elements like plot, character, and director. He did not apply this to how people first decide on a movie, but how such elements had an impact on a respondent's favourite movies. His research shows that viewers look to movies for fantasy fulfilment and emotional experience (Fischoff, 1998). His results indicated that drama was the most popular genre in terms of all-time favourite films.

\section{Research context}

In fact, there are still some things that going to a film theatre offers over such technological marvels as DVD or satellite channels. For example, by seeing a movie in a theatre, people can be the first on the block to say they saw that movie and discuss it. Another reason people go to the theatre could be the size of the screen: no TV or video-viewing device has yet been able to match the size of watching a movie on the big screen. While watching a movie on a big screen, a person can almost feel like they are in the movie itself. In sum, people will go to a movie for all sorts of reasons (Phillips, 1985; Austin, 1989; Brooker and Deborah, 2003; Freeland, 2009), and the current study wishes to know why they choose a certain movie based on what they knew or what media they have been exposed to beforehand, which is the backbone of the current study. Austin (1983 and 1989) sees the audience as discriminating in what they choose to watch of available movies, and he wishes to declare the reasons behind such discrimination. According to him, the factors, which influence the movie selection process, include the following: publicity and advertising, reviews, personal influence, story type, and production elements. These factors represent many of the variables examined in the current 
study with trailers included with advertising, reviews represented by critiques, story type representing genre, and personal influence representing word-of-mouth influence. The difference between Austin's example and the current study is the inclusions of director and actors into one element (i.e., production elements). The current study will look at a representative sample of Egyptian audiences and see which mean is the highest among the investigated variables of the study. Furthermore, Austin states that many tools could be used to look at audiences' behaviour with film, be they quantitative or qualitative. The current study will depend on quantitative methods by using Likert scales in its e-mail questionnaire survey.

Some other researchers focus their work on the film's ability to influence an audience. Noel Carroll, for example, analyzes the effect of emotions that film can produce in the audience (Plantinga and Smith, 2009). He sees genre as having the ability to elicit specific emotions, thus lending to the current study the idea that genre is important in analyzing movie-viewing choices. Plantinga and Smith support Carroll's idea of a film being able to elicit emotions. They see movies as being able to elicit such emotions as fear, happiness, anger, and pain: cinema more than any other art form has a way of drawing viewers into a situation that, for a moment, makes them a witness and sometimes an emotional participant to what is happening on screen (Plantinga and Smith, 2009). Vale (1982) reminds us as well that the spectator anticipates, evaluates, moves forward, feels suspense, experiences emotions, hopes and fears, is joyful and is depressed, satisfied and disappointed. In order to cause the spectator to undergo all these pleasant and unpleasant reactions and feelings, he must be interested, which gets back to the idea of previews and genre. On the other hand, Rosengren and his fellow researchers (1985) indicate that exposure to entertainment sources can also be used to regulate excitation. For example, a person who is bored may seek to go to an action picture to become excited or a highly excited person may want to see a movie that is more calm or soothing, like a love story. Consequently, and opposed to Carroll's ideas, this suggested that audience will choose a movie based on how they feel or how they want to feel, not just because of its genre. Speaking in psychological terms, Carroll, Vale and Plantinga and Smith's ideas form reasons why people may go to see a movie in the theatre, but they do not touch on why a specific movie choice was made. While acknowledging that movies are designed to make people feel a certain way, the current study will focus on looking at reasons why a movie was chosen to discover what media is most successful at getting people to sit in a theatre. It will look at the perspective of the individual audience member's reasons for choosing a certain movie based on media exposure rather than looking into their mindset for watching a movie.

David Sterritt, staff writer at the Christian Science Monitor, discussed talking about a movie with friends and family even after the movie was over, and how personal people would get when a movie they liked was put down by others. This indicates an inherent power in film over the audience, as well as the ability of word-of-mouth to influence audience members. In brief, word-of mouth can be an important factor in watching a movie (Plantinga and Smith, 2009). The current study wishes to see how this power develops by the many variables surrounding movie-viewing choice. Word-of-mouth (i.e., other people talking about a movie) will be one of the key variables in the current study.

Past research also suggested that many people go to the movies for identification (i.e., reducing the gap between film and spectator). Carroll, for example, describes audience members as wanting to identify with the characters they see on the screen (Plantinga and Smith, 2009). This speaks of being able to experience a movie-character's life in the theatre and return to the respondent's normal life when the lights come up (Burnett, 1999). A person could escape into another life by watching a movie. They see something on screen that would have some relation to something in their own life, perhaps an unrealized dream. While discussing the topic of movie-star, Jacqueline Rose, a researcher at Queen Mary and Westfield College in London, talks about the idea that the life of a celebrity would invite others to watch what he or she does, even if the celebrity was trying to remain more private (Rose, 2003). The current study wishes to see what effect, if any, the presence of a movie star has on a person's movie-viewing choice when going to a theatre. Will a person see a movie just because they like the celebrity or their previous movies? But the single idea of celebrity is only one reason why a person may be motivated to go see a particular movie. The current study will take into account movie stars as well as other variables including trailers, advertisements, critiques, genre, word-of-mouth, and the presence of a particular director. Sometimes even directors can be seen as celebrities.

\section{Research methods}

The questionnaire has been one of the best ways to research the uses and gratifications theory (Rosengren 
et al, 1985). The questionnaire is merited for being efficient with minimal problems of effort and cost, and it is the method used in the present study (Rosengren et al, 1985). While designing the study's survey, the researcher took in his account the following points which had to be regarded for producing an appropriate data-collecting instrument:

- The current study will focus only on why a certain movie was chosen among others that were available at the time, and on what basis an Egyptian audience chose that movie based on what s/he knew about the movie beforehand.

- The researcher wishes to focus on what is the primary motivator(s) to going to see a specific movie from the outside point of view of media usage, not what motivates a person internally to see a movie.

- The current study wishes to examine why people go to the movies but not their reactions to specific movie themes. In other words, the current study is not interested in the far-away aspects of finding audience likes and dislikes about a particular movie.

- The current study acknowledges the influence of advertising to get people to go to a movie, but the study is looking at advertisements in competition with other aspects of media use, including critiques, movie stars, word-of mouth and genre.

- The present study will ask respondents about their age and sex, however that data will not be used at the analysis stage of the research. The researcher is hoping that his study applies to all Egyptian audience, and not to segregate any one group's responses.

In order to construct the final questionnaire of the study, the researcher asked friends, students, co-workers, and fellow researchers what they thought were the reasons why they like to go to the movies. This initial informal questioning was conducted to group as much as possible of the reasons why people go see a specific movie at film theatres. The researcher received answers such as: movie critiques, movie trailers, general advertising (advertisements in newspaper, magazine, movie posters, and on TV), movie-star power, wordof-mouth, and the director of a film. This information was very helpful in determining the variables to be included within the main questionnaire of the study. The main questionnaire was designed to be selfexplanatory so that respondents will have ease in answering it. (A copy of the used questionnaire form is included within Appendix 1)

Respondents were asked to rate, on a scale of 0 to 10 , the extent to which seven factors influence their movie-viewing choices, with a rating of 10 means "heavy influence," and a score of 0 means "no influence at all." The seven factors were:

1. Critique Influence: for the present study, critiques were defined as non-academic writing on contemporary films, usually in newspapers and magazines (Blandford et al, 2006).

2. Preview Influence: trailers are those small previews of upcoming movies seen in the theatre or at home on TV (Blandford et al, 2006).

3. General Advertising Influence: general advertising includes advertisements in magazines, movie posters advertising an upcoming movie, advertisements for a movie seen in a newspaper, advertisements of a movie mentioned on the radio, movie stars promoting a movie on a TV show (Blandford et al, 2006).

4. Movie-Star Influence: a film star is a performer whose presence in a film can assure box-office success (Blandford et al, 2006).

5. Genre Influence: Genre is a category, kind, or type of art or cultural artifact with certain elements in common. In film, common genre elements include theme, narrative and stylistic conventions, motifs, character types, plots, and iconography (Blandford et al, 2006).

6. Word-of-Mouth Influence: word-of-mouth is defined in the current study as the response to a movie that is spread by those who have seen it and are talking about it and/or the buzz about a movie that is spread by the general public.

7. The Director Influence: This influence results when someone wants to see a movie in the theatre because they like the director's previous work.

\section{Participants selection process}

Beside being familiar with movies and going to film theatres and interested in participation as well, four main principles guided the selection of participants for this study's e-mail survey. Firstly, the participants must be Egyptian living in Egypt at the time of conducting the study's e-mail survey. Secondly, the sample 
should include a variety of ages from teenagers to seniors and elderly citizens, and not to be limited to a specific age range. Thirdly, focus was on the availability of an e-mail address that could be used to send the questionnaire to the participant. Therefore, participation in the questionnaire survey was limited only to participants who had e-mail accounts, which possibly created a threat of bias. Fourthly, respondents should be from different backgrounds and work or education experiences.

Nearly 1500 e-mail addresses were collected randomly through the Internet from Egyptian web sites such as societies, directories, lists, indexes, guides, groups, etc. It is assumed that the randomness in terms of selecting the participants has been partially ensured; the researcher did not depend on only one source to get the participants' e-mail addresses but on many web sites. Also, while collecting these addresses random approaches were adopted, such as selecting only every third or fourth name after a random start was indicated in each group of e-mail addresses. After collecting that huge number of e-mail addresses, the researcher had to choose those who were actually contacted for the survey purposes. Again, and depending on random techniques, the initial 1500 e-mail addresses were mixed together using suitable options of the Word software. Afterwards, random start points were indicated and an e-mail address was chosen after every specific number of e-mail addresses. The final number of Egyptian audiences the researcher decided to address with his questionnaire survey was 350 chosen randomly (Wimmer and Dominick, 2007).

\section{Results and Discussion}

Excluding those who filled out the survey totally wrong, those who do not go to the movies at all, those who live outside Egypt and those younger than 15 years of age, the final number of respondents who truly took part in the present study was 58 participants. Hence, it should be said that this study employed a rather limited sample which could have been expanded, depending primarily on time and money. Further, and after analyzing the age category question of the present study's questionnaire, it was found that the highest percentage of participants came from both the (15-20) and (21-25) age categories. The second highest age categories for this survey were the (26-30) and (31-35). The questionnaire did not elicit any responses from participants who are over the (46-50) age category. To a great deal, this matches with the known statistical reports which suggest that the majority of those who go to the movies are young. The collected data were processed afterwards using the SPSS software as shown below.

Summary statistics help make data more manageable by measuring central tendency and variability (Wimmer and Dominick, 2007). Mean (i.e., the average score of all responses given) and mode (i.e., the value that occurs most often) were calculated to answer the research questions and to examine which variables were the highest in mean and mode. This will aid in looking for which reasons people go to the movies the most out of all the reasons used in the questionnaire. (Please note that respondents used a 0-10 scale to give their opinions, with 0 meaning not at all and 10 meaning very influential.) The results of comparing means and modes are shown below (Figure 1).

Order by mean:

1) Genre $=6.38$

2) Movie stars $=5.91$

3) Trailers $/$ previews $=5.874$ ) Word-of-Mouth $=5.58$

5) Advertisements $=4.62$

6) Critiques $=3.47$

7) Director $=2.58$

This order indicates that respondents felt that genre and movie stars were of the highest interest to them in choosing a movie to see. The modes mirrored a similar sequence to the means. Order by mode:

1) Genre $=10$

2) Movie stars $=9$

3) Word-of-mouth and trailers $=$ both 7

4) Advertisements $=4$

5) Critiques and directors $=$ both 0

Analyzing the answers-scale for each question:

- When Egyptian respondents were asked to rate the influences of critiques on their movie viewing choice, 
the highest majority of respondents answered 0 to this question, indicating that they are not using critiques as an influence in their decision of watching a movie. This was different than the initial speculation in this study, where it was thought that respondents would highly consider the views of critiques before they made their movie choice at the theatre.

- Concerning the impact of watching trailers on movie-viewing choice, the highest majority of respondents answered 7 to this question, indicating a high influence of watching trailers on their movie-viewing choice. This was not the highest mode or mean, but it did have many respondents grading it as having a high influence on their movie-viewing choice. It is significant because a trailer usually gives some idea about genre and lists the primary stars of the movie. Both of these items, i.e. genre and movie stars, had the highest means and modes for the entire study. Genre and movie-star power were the biggest reasons behind an Egyptian audience's movie-viewing choice in this study.

- Concerning advertisements effect, the highest majority of respondents answered 4 to this question, indicating that it was a question that was most wavered on and could have affected overall respondent decision either way. Advertising companies would be smart to work on these respondents because these people could be the difference makers in deciding whether a person will be attending a movie in a theatre or not. A speculation would be to make the advertisements more like the trailers, giving a better idea about genre to an audience than a single catch phrase.

- For the two variables of genre and movie stars, respectively, there is sufficient evidence from this study to indicate that these two factors would be the highest in helping Egyptian audiences make their decision about what movie they want to see. The majority of the respondents gave the genre question a 10, which was the highest percent and frequency from all values by all respondents who answered the question in this category. There was also a majority among respondents who thought that movie-stars had a high influence on their movie choices. These respondents gave the movie-star question a 9 on the questionnaire form. Therefore, and according to the results of this study, it may be suggested that Egyptian audiences pay the most attention to the movie genre and the stars that appear in it when they choose a movie to watch at a film theatre.

- Concerning the influence of the director on movie-viewing choice, the mean was 2.58 and the mode was 0 . This indicates one of the lowest reasons why respondents go to the movies according to the current study. The majority of respondents gave the answer 0 for this question. This also indicates that the director is not a big influence on Egyptian audiences' movie-viewing choice and was less of a force than was originally speculated. It could be said that Egyptian audiences do not pay much attention to who directs a movie when they choose to watch it at a film theatre.

Using the same principles of mode and mean, the values for the question, where people rated how they found out about movies through various media (TV, Radio, Internet, magazines, newspapers, movie theatres, and word-of-mouth), were also examined (Figure 2). (Please note again that respondents used a 1-7 scale to give their opinions, with 1 meaning least helpful and 7 meaning most helpful.)

Order by mean:

1) $\mathrm{TV}=4.76$

2) Theatres $=4.72$

3) Word-of-mouth $=4.25$

4) Newspapers $=3.89$

5) Internet $=3.49$

6) Radio $=3.20$

7) Magazines $=2.75$

Order by mode:

1) TV, newspapers, and theatres $=$ all 7

2) Word-of-mouth $=3$

3) Radio, Internet, and magazines $=$ all 1

According to the above results, respondents find out about movies in theatres primarily from TV and the theatres themselves. The sources least selected by the respondents here were radio, Internet, and magazines. Word-of mouth and newspapers were somewhere in-between. In speculation, and by examining the results 


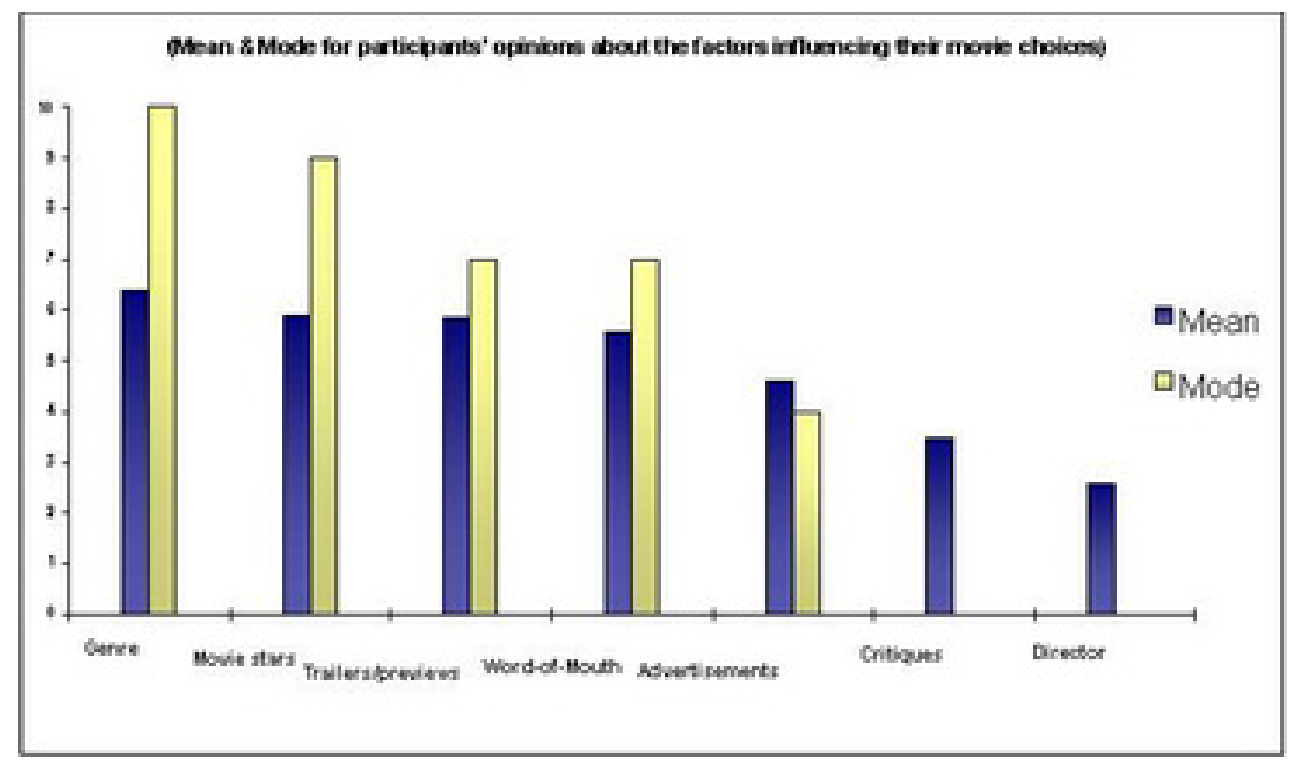

Figure 1: Figure 1

of this study, it would be advisable for advertisers to keep improving TV and theatre exposure for those choosing movies, and to improve existing ways that radio, the Internet, and magazines advertise movies. This could also be true because more of the Egyptian population has easier access to TV, even if they do not own one. There are TVs in such well-visited areas as shopping malls, restaurants, and big stores. On the other hand, not all the Egyptian audiences own a computer or have Internet access, however, the number of Internet users in Egypt is increasing gradually. It could be good to start advertising on the Internet by a written URL near the bottom of a movie poster or at the end of a TV advertisement. It would also be good to improve advertising in the radio and in magazines.

\section{Conclusions and recommendations}

It is always important to ask the question, "Did the study really investigate the proposed research question?" For the purposes of this study, the primary research questions were all geared to discover why Egyptian audiences go to the movies. Beside examining existing research as presented within different sections of this research paper, a sample of the Egyptian audiences were asked about what they base their movie-going behaviour on and why they choose specific movies to see. In fact, there may have been other reasons for Egyptian audiences going to the movies other than those used for questioning during this study, but the primary achievement was that Egyptian audiences, perhaps for the first time, were able to participate and to give their opinions.

Based on the findings of the present study, shown within the previous section, it could be suggested that there are high relations between Egyptian audiences' movie-viewing choices and movie stars, trailers, genre, advertisements and word-of-mouth. This means that Egyptian movie industry should focus on these factors/media in order to get people to go see a movie in the theatre. On the other hand, there was a low correlation between Egyptian audiences' movie-viewing choices and critiques and the director of the movie. This does not mean that such factors are not important in choosing a specific movie to watch by the Egyptian audiences, but perhaps they are not the primary reasons why people go see a movie in the theatre. In sum, the participants of the present study were basically concerned with the genre and the stars of a movie when thinking about the way they choose a movie to see at film theatres.

Further, the findings of this study could be used in different respects. For example, Egyptian film production and distribution companies would be advised to stop promoting various critics' talks about movies during the trailers and previews. This is because Egyptian audiences may not go to theatres because of what a critic wrote or said. The participants of the present study also felt the same about the director. As it was found during this study, Egyptian audiences do not really go to a movie because of the director. It may be 
suggested therefore that it is not always necessary for trailers or movie previews to bring up who directed what film because people will be paying primary attention to what the movie is about as this is the main reason why people go to the movies according to this study. The participants of the present study favoured genre the most. So, it would be in the best interest of Egyptian film production and distribution companies to focus on making better trailers and giving the genre of a movie without leading the audience on about the movie's details.

Lastly, it should be stated that the results of this study helped in showing that Egyptian film theatres are not in immediate danger of facing extinction and that Egyptian people will still be coming to see a movie in a theatre despite the existence of many new and advanced technologies available today which may compete with film theatres over audiences' leisure time and money.

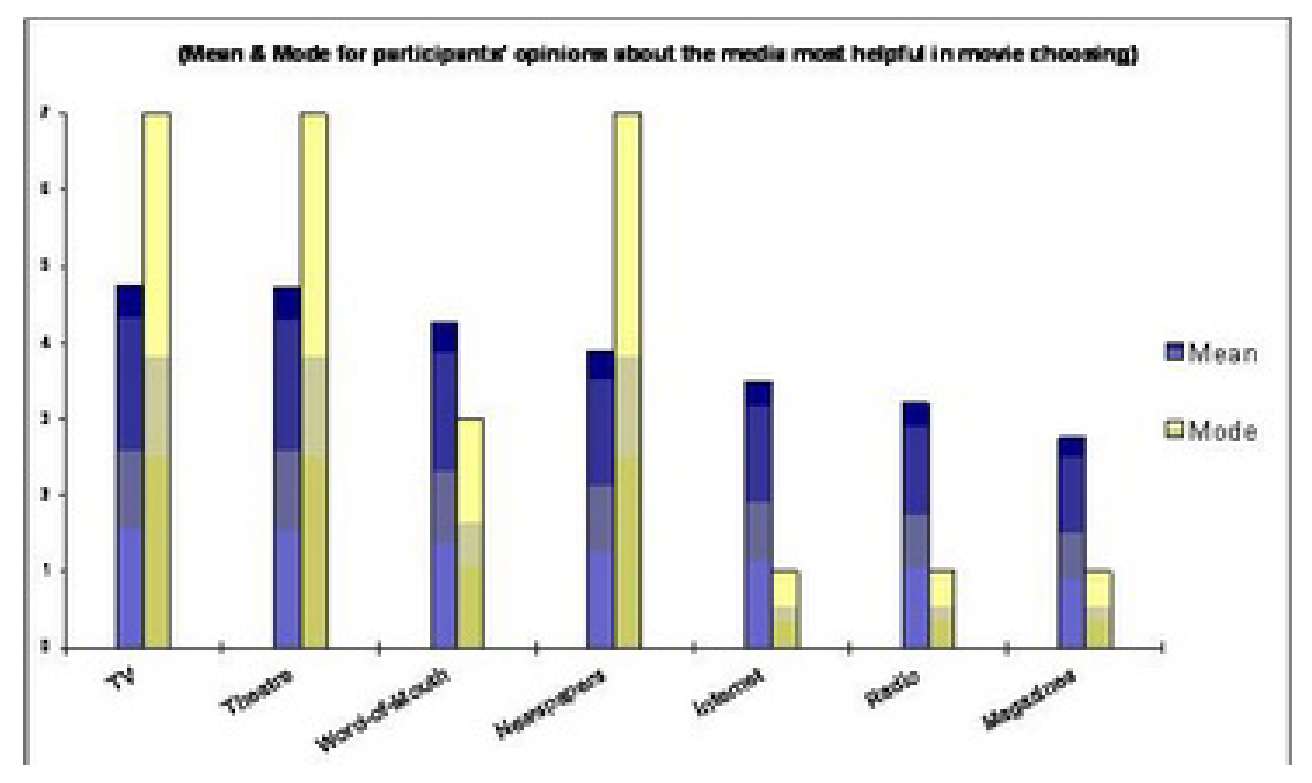

Figure 2: Figure 2

\section{References}

\section{References}

Austin, B. (1983): The Film Audience: An International Bibliography of Research. The Scarecrow Press, Inc.

Austin, B. (1989): Immediate Seating: A Look at Movie Audiences. Wadsworth, Inc.

Blandford, S.; Barry, K.; and Jim, H. (2006): The Film Studies Dictionary. Oxford University Press, Inc.

Brooker, W.; and Deborah, J. (2003): The Audiences Studies Reader. London: Routledge.

Burnett, R. (1999): Explorations in Film Theory: Selected Essays from Cine-Tracts. Indiana University Press.

Carroll, N. (1990): The Philosophy of Horror or Paradoxes of the Heart. Routledge, Chapman and Hall, Inc.

Fischoff, S. (1998): 'Film-Choice.' Journal of Media Psychology.

www.calstatela.edu/faculty/sfischo/movie3.html

Freeland, C. (2009): Cognitive Science and Film Theory. For the American Society for Aesthetics Panel on Cognitive Science and the Arts. 
http://www.hfac.uh.edu/cogsci/CogSciFilmTheory.html

Fuller, K. (1996): At the Picture Show: Small-Town Audiences and the Creation of Movie Fan Culture. The Smithsonian Institute.

Litman, B. (1983): 'Predicting the Success of Theatrical Movies: An Empirical Study'. Journal of Popular Culture. Spring 1983: 159 - 171.

Newspaper Advertising Bureau (1986): 'Movie Going in the United States.' Newspaper Advertising Bureau, Inc.

Phillips, W. (1985): Analyzing Films: A Practical Guide. CBS College Publishing.

Plantinga, C.; and Smith, M. (2009): Passionate Views: Film, Cognition, and Emotion.

http://www.nottingham.ac.uk/film/journal/bookrev/passionate_views.htm

Rose, J. (2003): The Cult of Celebrity. London Review of Books.

Rosengren, E.; Lawrence W.; and Philip, P. (1985): Media Gratifications Research. Sage Publications.

Salwen, M.; and Stacks, W. (2006): An Integrated Approach to Communication Theory and Research. Lawrence Erlbaum Associates, Inc.

Vale, E. (1982): The Technique of Screen and Television Writing. Prentice Hall, Inc.

Wimmer, R.; and Dominick, J. (2007): Mass Media Research: An Introduction. Wadsworth Publishing Company.

\section{Appendix 1: (Sample of questionnaire form used)}

\section{A - Personal questions}

Name (not obligatory):

Nationality:

Sex:

Age: (Underline the age category that fits you best from the ones shown below)

15-20 / 21-25 / 26-30 / 31-35 / 36-40 / 41-45 / 46-50 / 51-55 / 56-60 / Above 60

Where do you live now?

How many times a year do you see a movie at a film theatre?

\section{B - Study questions}

On a scale of 0 to 10 (with 0 meaning not at all and 10 meaning very influential) please tell us how much does each factor from the following factors make you want to go to a film theatre to watch a specific movie:

1. Critiques in the newspaper, magazines, etc.?

$0-1-2-3-4-5-6-7-8-9-10$

Not at all <-----------> Very influential

2. Trailers on television and in the theatre?

$0-1-2-3-4-5-6-7-8-9-10$

Not at all <-----------> Very influential

3. Advertisements on television, newspapers, magazines, radio, and the Internet? 
$0-1-2-3-4-5-6-7-8-9-10$

Not at all <------------> Very influential

4. Stars (actors/ actresses) in a movie?

$0-1-2-3-4-5-6-7-8-9-10$

Not at all <------------> Very influential

5. Genre (e.g., action, comedy, and horror) of a movie?

$0-1-2-3-4-5-6-7-8-9-10$

Not at all <------------> Very influential

6. Word of mouth?

$0-1-2-3-4-5-6-7-8-9-10$

Not at all <------------> Very influential

7. The director of a movie?

$0-1-2-3-4-5-6-7-8-9-10$

Not at all <------------> Very influential

Finally, and from your point of view and experience, please rate the following seven media types, on a scale of 1 to 7, according to their help to you in knowing about new film releases and in deciding to go seeing a specific movie in a film theatre (with 1 meaning least helpful and 7 meaning most helpful)?

Word of Mouth

Radio

Magazines

Newspapers

The Internet

Movie Theatres

TV

\section{Author Information}

Mustafa Mahmoud YOUSRY, PhD, is Associate Professor and researcher at the Department of Photography, Cinema, and Television, Faculty of Applied Arts at Helwan University, Dokki, Giza, Egypt. 